\title{
Médiévales
}

Langues, Textes, Histoire

63 | automne 2012

Philosophies morales

François FORONDA, Christine BARRALIS, Bénédicte SÈRE (dir.), Violences souveraines au Moyen Âge. Travaux d'une école historique

Paris, Presses Universitaires de France, 2010, 284 p. (Collection Le nœud gordien)

\section{Christelle Balouzat-Loubet}

\section{(2) OpenEdition}

\section{Journals}

Édition électronique

URL : https://journals.openedition.org/medievales/6897

DOI : $10.4000 /$ medievales. 6897

ISSN : $1777-5892$

Éditeur

Presses universitaires de Vincennes

Édition imprimée

Date de publication : 15 décembre 2012

Pagination : 176-178

ISBN : 978-2-84292-353-2

ISSN : 0751-2708

Référence électronique

Christelle Balouzat-Loubet, « François foronda, Christine barralis, Bénédicte sère (dir.), Violences souveraines au Moyen Âge. Travaux d'une école historique », Médiévales [En ligne], 63 | automne 2012, mis en ligne le 15 janvier 2013, consulté le 24 avril 2022. URL : http://journals.openedition.org/ medievales/6897; DOI : https://doi.org/10.4000/medievales.6897

Ce document a été généré automatiquement le 24 avril 2022.

Tous droits réservés 


\section{François FORONDA, Christine BARRALIS, Bénédicte SÈRE (dir.), Violences souveraines au Moyen Âge. Travaux d'une école historique}

Paris, Presses Universitaires de France, 2010, 284 p. (Collection Le nœud gordien)

\section{Christelle Balouzat-Loubet}

1 Cet ouvrage collectif, publié sous la direction de François Foronda, Christine Barralis et Bénédicte Sère, est dédié à Claude Gauvard, à qui il fut remis à l'occasion de son départ en retraite. Il rassemble des contributions portant sur un thème cher à la dédicataire, devenu sous sa plume un objet historique à part entière: la violence. Les trois parties du volume sont fidèles à l'héritage gauvardien. Une première partie («Procédures et gouvernement judiciaire») porte sur le fonctionnement de la justice médiévale. Les contributions de la seconde partie («La part du négatif») montrent que la violence est une composante essentielle de la société médiévale sur laquelle le pouvoir princier tente progressivement d'étendre son contrôle (à quoi s'attache la troisième partie: «Le choc souverain»).

2 La première partie s'ouvre sur deux articles s'appuyant sur le droit savant pour présenter deux points de la théorie judiciaire médiévale. Y. Mausen rappelle ainsi que le procès, source potentielle d'injustice, suscite au Moyen Âge la méfiance. C'est pourquoi les traités de droit érigent des règles garantissant l'équité de la procédure. $T$. Kouamé montre quant à lui que le concept de légitime défense - légitime défense du corps et légitime défense des biens - a nourri les réflexions des Glossateurs aux XII et $\mathrm{XIII}^{\mathrm{e}}$ siècles. L'exercice de la justice est donc pensé, codifié. La mise en pratique des préceptes romano-canoniques reste néanmoins variable, comme le montrent les contributions suivantes, qui partent de l'analyse de situations concrètes pour cerner la procédure judiciaire. Sébastien Hamel et Louis de Carbonnières s'intéressent à l'application de la peine de mort, respectivement dans les juridictions municipales et au 
Parlement de Paris. Ces deux études s'accordent à dire que le droit de condamner à mort, quoique peu usité par les juridictions médiévales, reste un privilège constitutif de la souveraineté, auquel les institutions sont attachées. Les échevins de Saint-Quentin se sont ainsi battus pour lever les ambiguïtés de leur charte communale et faire reconnaître leur compétence en matière criminelle. La question du bris d'asile par les serviteurs de l'État sous le règne de Charles V (C. Barralis) illustre les rapports entre justice royale et justice ecclésiastique; elle montre aussi comment le souverain cherche à s'imposer comme le seul garant de l'ordre public. La présentation d'une amende honorable à Reims en 1456 permet à $\mathrm{V}$. Beaulande-Barraud d'évoquer les spécificités de la justice capitulaire, tout en montrant l'importance des rituels de restauration de l'honneur dans le règlement des conflits. À travers l'étude de l'«émeute» du 11 juillet 1497 à l'Hôtel-Dieu de Paris, C. Jéhanno montre que l'enquête réalisée sur le déroulement des faits n'est pas une simple juxtaposition de témoignages mais un récit qui construit un objet, la violence. Les deux dernières contributions concernent davantage la question de l'administration judiciaire. C. Bellanger présente la figure du sergent à travers l'enluminure à la fin du Moyen Âge, tandis que J. Claustre s'interroge sur la mise en place d'une administration carcérale au Châtelet au cours du Xve siècle.

3 Cette première partie montre donc une institution judiciaire en construction, dont les références puisent aux sources du droit mais aussi aux actes de la pratique. Les études suivantes s'intéressent logiquement à ce qui menace l'ordre public et justifie l'exercice de la justice: la violence. Comme le montre B. Sère à travers l'analyse du Super Rhetoricorum de Gilles de Rome, la violence, parce qu'elle est le produit de rapports sociaux guidés par la défense de l'honneur et de la fama, est constitutive de la société médiévale. Le Moyen Âge distingue néanmoins entre la violence acceptée et la violence réprouvée (H. Carrier): si les «beaux faits» sont admis, et même magnifiés dans la littérature chevaleresque, les actes violents contraires au code de l'honneur sont sévèrement jugés et portent atteinte à la réputation de leur auteur. Les récits de l'exécution du bâtard de Vaurus (B. Bove) et de la désobéissance du damoiseau de Commercy (V. Toureille), dans lesquels l'autorité souveraine justifie le recours à la peine de mort, permettent de cerner ce qui est perçu comme une violence extrême dans la société de la fin du Moyen Âge. Il ne faut pas croire cependant que le pouvoir détermine seul les limites entre violence tolérée et violence réprimée: l'opinion publique joue aussi un rôle dans la définition de ce qui doit ou non être considéré comme une menace à l'ordre public. L'autorité publique elle-même doit se justifier face à ses sujets: dans la première moitié $\mathrm{du} \mathrm{Xv}^{\mathrm{e}}$ siècle, à Toulouse, l'entrée en guerre fait débat (X. Nadrigny) tandis que la proclamation d'une décision peut provoquer une réaction violente de la population, qui marque ainsi son opposition à ce qui est crié (N. Offenstadt). Les deux derniers articles (D. Péricard-Méa et F. Delivré) permettent finalement d'élargir la perspective en s'intéressant à la perception de la violence en Castille et dans l'État pontifical.

$4 \mathrm{Au}$ terme de cette deuxième partie, dont les réflexions touchent largement à l'anthropologie et à la sociologie, la violence apparaît bien comme un élément constitutif de la société médiévale. Cette violence, le pouvoir souverain cherche néanmoins à la réguler, comme le montre la troisième partie. L'autorité publique, qui s'informe sur les crimes commis grâce à l'enquête, dispose de divers outils pour maintenir l'ordre: la répression, la composition, la grâce et le pardon sont autant de modes de règlement des conflits qui fondent les relations entre l'autorité judiciaire et 
les justiciables (O. Canteaut, P. Charon). La définition des prérogatives royales en matière judiciaire fait l'objet d'âpres négociations entre le souverain et ses sujets: les Aragonais, qui ont obtenu en 1283 un privilège interdisant au monarque de juger un crime par inquisitionem, doivent lutter pour en garantir l'application dans la pratique (M. Charageat); dans la deuxième moitié du XIV ${ }^{e}$ siècle, les négociations menées par Louis de Male pour la libération de Yolande de Flandre mènent finalement à une réflexion sur le statut des grands du royaume au sein de la justice royale (M. Bubenicek). Défié dans son autorité - lors de l'élection épiscopale parisienne de 1492 (V. Julerot) - ou bien trahi par un proche - Jacques d'Armagnac, jugé en 1476-1477 (É. Cottereau-Gabillet) -, le roi n'hésite pas à intenter des procès, à juger et à condamner. Il n'en reste pas moins que la violence royale, comme toute autre violence, doit être légitime: le meurtre de Pierre $\mathrm{I}^{\text {er }}$ de Castille par Henri de Trastamare, soutenu par Charles V, embarrasse grandement le souverain français (F. Foronda) et l'assassinat du duc d'Orléans suscite d'importants débats doctrinaux pour savoir si la prohibition de l'homicide s'applique également au monarque (C. Leveleux-Texeira). P. Prétou rappelle enfin que le haro, ou clameur publique, devient à la fin du Moyen Âge une forme de contestation de l'administration judiciaire s'opposant à la sujétion inhérente à la construction de l'État.

5 Les vingt-six contributions rassemblées dans cet ouvrage, fondées sur des sources diverses, constituent une magistrale synthèse sur la violence médiévale analysée sous toutes ses facettes, juridiques, institutionnelles, sociales, politiques. Elles montrent que la violence, constitutive d'une société dans laquelle est loué le «beau fait» et autorisée la vengeance, n'en est pas moins bornée par une conscience aiguë de ce qui nuit à l'ordre public. La régulation de la violence, dont le pouvoir souverain cherche à s'assurer le monopole, est finalement une œuvre collective: la société médiévale dans son ensemble obéit à un code de comportement, dicté par l'honneur, tardivement et parfois difficilement normalisé par le roi et les princes.

6

Dans cet ouvrage sont brillamment réinvesties les problématiques développées par Claude Gauvard tout au long de sa carrière. Ses recherches pionnières sur les thèmes abordés ici ont inspiré nombre de jeunes chercheurs qui, par l'objet et la qualité de leurs réflexions, rendent un bel hommage à celle qui leur a ouvert la voie. 